\title{
AN ECOLOGICAL GENETIC ANALYSIS OF THE SETTLING BEHAVIOUR OF A MARINE POLYCHAETE:
}

\section{PROBABILITY OF SETTLEMENT AND GREGARIOUS BEHAVIOUR}

\author{
TRUDY F. C. MACKAY* and ROGER W. DOYLE \\ Biology Department, Dalhousie University, Halifax, Nova Scotia, Canada B3H 4JI
}

Received 4.xii.75

\begin{abstract}
Summary
The settling behaviour of larvae of Spirorbis borealis from several ecologically contrasting environments was analysed in terms of means and genetic variances (the latter expressed as heritability) of two components-the probability of settling when presented with a particular substrate, and the gregarious behaviour of the larvae. Larval behaviour differed markedly according to the population from which they came: animals from a sheltered tidepool prefer Ascophyllum, and are distinctly gregarious, while those from a semi-exposed embayment settle much more readily on Fucus and are not as gregarious. Animals collected from an environmental cline ranging in conditions from tidepool-like to embayment-like exhibit a corresponding range in behaviour. This interpopulation variation in character means is interpretable in terms of adaptation to differential selection pressures known to be acting on the populations; consideration of intra-population genetic variances gives an indication of the mechanism of the adaptation.
\end{abstract}

\section{INTRODUGTION}

THERE are basically two approaches to the characterisation of the genetic architecture of natural populations; the first involves consideration of characters controlled by one or a few genes, and the second, quantitative or metric characters. Genetic differentiation in the first type of study can be demonstrated by differences in gene frequency among populations, and correlation of the character with habitat type, an approach which has been followed in many of the earlier ecological genetic studies (Ford, 1965). The biochemical technique of electrophoresis has vastly extended the number of characters which may be analysed in this manner, however, this approach is restricted in scope in that few evolutionarily important traits are under control of a single major gene. Only in a few cases (e.g. Koehn and Rasmussen, 1967; Schopf and Gooch, 1971) have electrophoretic variants been found to be correlated with an environmental variable.

Investigation of the genetics of quantitative characters, on the other hand, affords a method by which we may directly study the components of fitness. Biometrical techniques developed in the context of plant and animal breeding enable one, through the knowledge of genetic correlations among relatives, to partition the observed phenotypic variance into genetic and non-genetic components. Depending on the complexity of the experimental design employed, the genetic variance may be further partitioned

* Present address : Department of Genetics, University of Edinburgh EH9 3JN.

$40 / 1-A$ 
into additive and non-additive (dominance, epistatic) components. These techniques have been successfully applied in many cases to the assessment of the degree and nature of the quantitative variation in a wide variety of natural populations: the poppy has been extensively investigated in this manner (e.g. Lawrence, 1965; Gale et al., 1976), as have several fungi (Simchen, 1967; Butcher et al., 1972), and, of course, Drosophila (Kearsey and Kojima, 1967; Barnes and Kearsey, 1970). However, rarely have these studies been conducted in conjunction with an analysis of the ecological situation in relation to the character of interest (but see Doyle, 1974; Chapman, 1974; Newkirk and Doyle, 1975). Consequently, the object of this work is to investigate, using the tools of biometrical genetics, and within the framework of ecological genetics, the settling behaviour of the serpulid polychaete, Spirorbis borealis.

Spirorbis is common along the coast of Nova Scotia; the sessile adults are found epiphytic upon various substrata, particularly members of the genera Fucus and Ascophyllum. The pelagic trochophore larvae settle upon one of the available substrates within 24 hours after release from the adult. The choice of substrate is thus the critical "decision" the animal makes and traits associated with this behaviour are therefore of particular interest. Previous studies have indicated that there is a substrate preference of $S$. borealis under experimental conditions for algae of the genus Fucus ( $F$. edentatus, $F$. vesiculosis, and $F$. serratus) over other substrates, including Ascophyllum and clean petri plates (Knight-Jones, 1953; deSilva, 1962). We have observed that the strength of this preference, when tested in the laboratory, differs according to the ecological conditions experienced by the animals, as does the distribution of the animals on the algal substrates in the field (Doyle, 1975). Knight-Jones et al. (1971) have also observed interpopulation differences in substrate preference of $S$. spirorbis, which were maintained under laboratory conditions, suggestive of a genetic component of this behaviour.

The phenomenon of gregariousness of the larvae has also been observed (Knight-Jones, 1951; Wiseby, 1960). Knight-Jones (1951) found that 77 per cent of freshly liberated larvae chose to settle on Fucus serratus with previously settled adults rather than bare Fucus. Mackay (1974) found that the strength of this property (as measured by change in probability of settlement with increasing density of larvae) varied as habitat.

The larval characters chosen for study were therefore "probability of settlement within 24 hours on a given substrate" and "gregarious settling behaviour"; for each the components of variation were partitioned among and within populations, and heritabilities were computed for each population.

\section{Methods}

(i) Ecological comparison of collection sites

Three populations of Spirorbis were chosen as representing contrasting ecological situations. The first was a large sheltered middle-shore tidepool (the "Hulda" tidepool of Doyle, 1975) near Peggy's Cove, Nova Scotia; the second, a semi-exposed embayment at Terence Bay, N.S.; and the third population (the "Fjord") an inlet approximately $200 \mathrm{~m}$ long near Polly 
Gove, N.S. Spirorbis chooses as substrate Fucus species (including F. edentatus and $F$. vesiculosis) at Terence Bay, although Ascophyllum is present in equal abundance and is readily accessible. They settle primarily on Ascophyllum at the Peggy's Cove location, in the absence of any other suitable fucoid. The distribution of animals on the algal substrates is somewhat more complex in the Fjord-animals are found both on Fucus and Ascophyllum all along the inlet-but the proportion of the population settling on Ascophyllum changes as one moves toward the mouth of the linlet. Whereas in the "Inner" Fjord (farthest from the open sea) there are from 10-100 animals found on Fucus for every one on Ascophyllum, the distribution in the "Outer" Fjord (closer to the mouth of the inlet) more nearly approximates a ratio of $1000+$ Fucus settled animals for every one on Ascophyllum. The proportion of Fucus to Ascophyllum plants also changes in that there are fewer Fucus than Ascophyllum plants in the Inner Fjord, but they are in equal abundance in the Outer Fjord. The Fjord was thus chosen to represent a cline in conditions from "Peggy's Cove-like" (Inner Fjord) to "Terence Bay-like" (Outer Fjord).

\section{(ii) Experimental technique}

Algae bearing Spirorbis from each of these populations (Terence Bay; Peggy's Cove; Outer Fjord, Fucus; Outer Fjord, Ascophyllum; Inner Fjord, Fucus; and Inner Fjord, Ascophyllum) were maintained in the laboratory in tanks of running sea-water at ambient temperatures. Animals were fed regularly with a suspension of phytoplankton (Platymonas, Phaeodactylum, and/or Thalassiosira).

Spirorbis is hermaphroditic; oogonia which develop in the female segments are fertilised by uptake of sperm into the shell cavity. Embryos are enclosed in a transparent envelope-like structure to form a discrete embryo chain which is incubated within the shell of the animal. Crossfertilised larvae were obtained by opening the calcareous shell of animals fertilised in the field and dissecting out the embryo chain; if the chain was at the most advanced stage of development larvae "spontaneously" released within a 20-minute period and were used in the experiment. DeSilva (1958) has demonstrated that even artificially liberated larvae by breaking the transparent covering does not significantly alter larval behaviour with respect to capability of metamorphosis and choice of substrate when compared to naturally liberated larvae.

The actual experiment consisted simply of introducing groups of 10 larvae into petri dishes containing sea-water plus either five $1-\mathrm{cm}$ square pieces of Fucus or five 3-cm long Ascophyllum fronds, none of which had previously borne Spirorhis. The dishes were incubated for 24 hours at $14^{\circ} \mathrm{C}$, after which the total number of larvae settled on each frond was counted. (It should be noted here that animals which remain unsettled after this period are not necessarily dead but may still be actively swimming or have not yet completed metamorphosis.) Each dish constitutes one replicate; there were up to four replicates per family, with approximately 30 families analysed for each population. 


\section{(iii) Heritabilities of probability of settlement}

The character " probability of settlement given a particular substrate" is phenotypically discontinuous in expression, but the behaviour within self-fertilised families does not seem to follow simple Mendelian rules of segregation; we may therefore consider the nature of inheritance to be polygenic and analyse it as a threshold character. Analysis of all-or-none traits has been examined by Wright (1933, 1934), Lush et al. (1948), Robertson and Lerner (1949), and Dempster and Lerner (1950), who assumed an underlying continuity with a threshold imposing discontinuity upon the phenotypic expression of the trait. Heritability is calculated from the percentage data $\left(h_{p}^{2}\right)$ either by analysis of variance for binomial datathe procedure adopted here-(Lush et al., 1948), in which case $h_{p}^{2}$ is $r$ times the intraclass correlation coefficient, or from a $2 \times \mathcal{N}$ chi-square analysis (Robertson and Lerner, 1949), in which case $h_{p}^{2}$ is a function of the heterogeneity chi-squared in the $2 \times \mathcal{N}$ table. However, because on a percentage scale variances differ according to the mean, probit transformation is advised as it makes the genetic variance independent of the threshold value in the population: The genetic variance on the underlying scale

$$
=\sigma_{x}^{2}=\left[h_{p}^{2} \cdot \bar{p}(1-\bar{p})\right] / \bar{z}^{2}
$$

where $\bar{p}$ is the mean incidence in the population, and $\bar{z}$ is the height of the ordinate of the standard normal curve corresponding to the abscissa value which cuts off a tail of area $\bar{p}$. Heritability on the probit scale is $h_{x}^{2}=\sigma_{x}^{2} /\left(1+\sigma_{x}^{2}\right)$, which may be compared to additive heritability on the percentage scale by the relationship $h_{p a}^{2}=\left(\bar{z}^{2} \cdot h_{x}^{2}\right) /(\bar{p}(1-\bar{p}))$.

It is relevant at this point to mention an additional source of covariance which may serve to inflate the between family component of variance to an unknown but possible significant extent: this is the common environment, or maternal, effect caused by the incubation of embryo chains within the shell of the female parent. A more sophisticated design than that employed here is necessary to remove and estimate this source of covariance.

\section{(iv) Measurement of gregarious behaviour}

The degree of gregarious behaviour is quantified in terms of Lloyd's Index of Patchiness (Pielou, 1974), a modified variance to mean ratio, corrected for mean density. It is analogous to the classical variance to mean ratio in that the expectaton given a random distribution is 1 , values greater than 1 indicating aggregation and less than 1 overdispersion. The variance of the index is defined, enabling comparison of estimates from different populations.

Lloyd's Index of Patchiness for populations may be computed by considering each algal frond used in the experiment described above as a sampling unit, and the number of worms settled on each recorded irrespective of genetic sub-groups. To check whether the measure thus obtained was inflated by uncontrolled variance among the fronds, a separate experiment, in which animals settled on the surface of petri dishes evenly coated with bacterial film, was performed. Each dish was divided into $641 \mathrm{~cm}^{2}$ quadrats, and the patchiness index computed. The genetic component of 
variability within each population was determined by computing patchiness indices for each replicate (for which three or greater larvae had settled) and partitioning the variance among and within families as usual.

\section{GeNETIC INFERENCES FROM THE BREEDING STRUCTURE OF SPIRORBIS POPULATIONS}

To compute heritability one needs to know exactly the degree of relationship among members of a family $-r$-which varies from 0.25 for half-sib families to 0.5 for full-sib families. With Spirorbis one is forced to draw inferences from the natural breeding scheme. The first assumption is that fertilisation is by a random sample of sperm from the whole populationthis seems eminently reasonable in view of the mass release of motile male gametes into the sea. Not so reasonable is the assumption that members of an embryo chain are related as half-sibs, each egg being fertilised by a different male parent, or as full-sibs produced by either self-fertilisation or by sperm from a single individual. The degree of relationship is in all probability more close to that of half-sibs than full-sibs, in view of the abovementioned method of spawning and the large population sizes involved; at any rate this is the alternative adopted. This procedure maximises heritability estimates.

One further point to be considered is that it is possible the populations are somewhat inbred, caused by a degree of self-fertilisation, mating among individuals settled upon a single plant, seasonal variation in effective population size, or a combination of all three. Dr E. Zouros (personal communication) has conducted an electrophoretic survey of the populations concerned at the xanthine dehydrogenase $(\mathrm{XDH})$ and aldehyde oxidase (AO) loci, and has computed Wright's inbreeding coefficient, F, for each. The estimates vary wildly (from small and negative to 0.451 ), with that from $\mathrm{XDH}$ consistently higher than $\mathrm{AO}$, and a combined estimate from both loci is not available for each population, but the best estimates are presented below:

\begin{tabular}{lcl}
\multicolumn{1}{c}{ Population } & $\mathrm{F}$ & Locus used to estimate F \\
Terence Bay & 0.277 & $\mathrm{XDH}+\mathrm{AO}$ \\
Peggy's Cove & 0.267 & $\mathrm{XDH}$ \\
Fjord (Inner+Outer) & 0.256 & $\mathrm{AO}$ (Inner), XDH (Outer)
\end{tabular}

One must therefore modify the heritability estimate by multiplying the intra-class correlation by a factor $4 /(1+F)$ (Kempthorne, 1969), thus adopting the half-sib hypothesis and correcting for the observed degree of inbreeding.

\section{Results}

(i) Probability of settlement on Fucus and on Ascophyllum

(a) Population means

The proportions of larvae which settled on Fucus and Ascophyllum are given for each population in table 1 . Since the absolute magnitude of the response differs for each population, the difference between the proportion 
settled on Fucus and on Ascophyllum was taken as a measure of the degree to which the animals "prefer" to settle on one or the other substratea negative measure means they settle more on Ascophyllum, the value zero indicates the animals settle equally frequently on either substrate, while a positive value indicates greater settlement on Fucus. (The word " prefers" is here used loosely, since no actual choice of substrate is involved.)

TABLE 1

Proportions ( \pm standard error) of larvae settled on Fucus and Ascophyllum

\begin{tabular}{|c|c|c|c|}
\hline \multirow[b]{2}{*}{ Population } & \multicolumn{2}{|c|}{ Substrate } & \multirow[b]{2}{*}{ Difference } \\
\hline & Fucus & Ascophyllum & \\
\hline Terence Bay & $0.838 \pm 0.011$ & $0.471 \pm 0.015$ & 0.367 \\
\hline Peggy's Cove & $0.374 \pm 0.015$ & $0.654 \pm 0.015$ & $-0 \cdot 280$ \\
\hline Outer Fjord, Fucus & $0.919 \pm 0.008$ & $0.575 \pm 0.015$ & $0 \cdot 344$ \\
\hline Outer Fjord, Ascophyllum & $0 \cdot 526 \pm 0.016$ & $0 \cdot 245 \pm 0.015$ & $0 \cdot 281$ \\
\hline Inner Fjord, Fucus & $0.538 \pm 0.014$ & $0.267 \pm 0.014$ & $0 \cdot 271$ \\
\hline Inner Fjord, Ascophyllum & $0 \cdot 350 \pm 0 \cdot 014$ & $0.293 \pm 0.017$ & $0 \cdot 057$ \\
\hline
\end{tabular}

It can be seen that the Terence Bay animals settle much more frequently on Fucus than Ascophyllum, while the reverse is true of the animals from Peggy's Cove. The Fjord populations exhibit a gradient in settling frequencies corresponding to the geographical cline, from settling predominantly on Fucus (Outer Fjord, Fucus) to no difference in settlement on either substrate (Inner Fjord, Ascophyllum).

\section{(b) Within population variances}

The analyses of variance for larval settlement on each substrate are given in table 2 . In every case there was significant added variation among families at the 5 per cent level, with the exception of the Outer Fjord, Fucus population (which had very little total phenotypic variation). Significant variation among replicates was also generally observed; since one would ordinarily expect the among and within replicate components to be of the same order, this is attributable to the phenomenon of gregarious settlement.

Table 3 summarises the various heritability estimates which may be calculated from the observed intra-class correlations. It is most interesting that for several populations the heritability estimates seem to differ according to the substrate presented. The Terence Bay, Outer Fjord, Fucus, and Inner Fjord, Fucus populations all have higher point estimates of heritability of settlement on Ascophyllum than Fucus, while the Peggy's Cove population has a higher heritability of settlement on Fucus than Ascophyllum. Although these estimates are not statistically different from one another (indeed, with heritabilities of the magnitude observed the size of experiment necessary to attain the requisite precision for statistical significance is practically prohibitive), the qualitative trend is that the rarer response is possessed of a greater degree of genetic variability. It should be borne in mind that the effect of common environment mentioned above may have increased the magnitude of these estimates, but there is no reason to suppose the pattern observed should be likewise affected. 


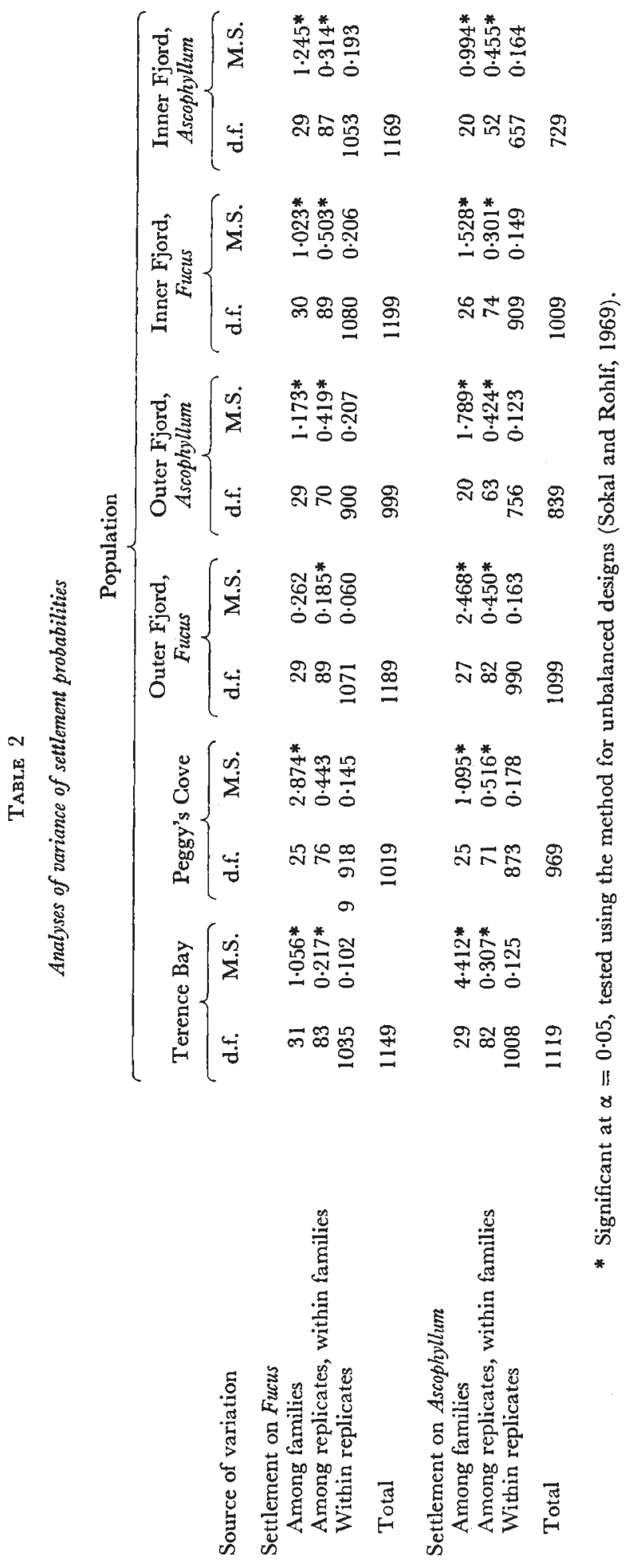


TABLE 3

Heritability estimates ( \pm standard error) of " settlement in 24 hours" on Fucus $(F)$ and Ascophyllum $(A)$

\begin{tabular}{|c|c|c|c|c|c|}
\hline \multirow[b]{2}{*}{ Population } & \multirow[b]{2}{*}{ Substrate } & \multicolumn{4}{|c|}{ Heritability estimates } \\
\hline & & $h_{p}^{2}$ & $h_{p}^{2}, \mathrm{~F}$ & $h_{p a}^{2}$ & $h_{p a}^{2}, \mathrm{~F}$ \\
\hline \multirow{2}{*}{ Terence Bay } & F & 0.672 & 0.526 & $0 \cdot 269 \pm 0.091$ & $0.242 \pm 0.075$ \\
\hline & A & $1 \cdot 740$ & $1 \cdot 363$ & $0 \cdot 465 \pm 0.134$ & $0.433 \pm 0 \cdot 114$ \\
\hline \multirow[t]{2}{*}{ Peggy's Cove } & $\mathrm{F}$ & $1 \cdot 048$ & 0.827 & $0 \cdot 388 \pm 0 \cdot 127$ & $0.353 \pm 0 \cdot 104$ \\
\hline & A & $0 \cdot 280$ & 0.222 & $0.191 \pm 0.083$ & $0 \cdot 162 \pm 0.068$ \\
\hline \multirow[t]{2}{*}{ Outer Fjord, Fucus } & $\mathrm{F}$ & $0 \cdot 108$ & 0.086 & $0.080 \pm 0.048$ & $0.067 \pm 0.040$ \\
\hline & A & $0 \cdot 840$ & $0 \cdot 669$ & $0 \cdot 360 \pm 0 \cdot 113$ & $0.324 \pm 0.098$ \\
\hline \multirow[t]{2}{*}{ Outer Fjord, Ascophyllum } & $\mathrm{F}$ & $0 \cdot 368$ & $0 \cdot 293$ & $0.233 \pm 0.088$ & $0.200 \pm 0.072$ \\
\hline & A & 0.728 & 0.580 & $0 \cdot 308 \pm 0 \cdot 121$ & $0 \cdot 278 \pm 0 \cdot 102$ \\
\hline \multirow[t]{2}{*}{ Inner Fjord, Fucus } & $\mathrm{F}$ & $0 \cdot 208$ & $0 \cdot 166$ & $0 \cdot 157 \pm 0.066$ & $0 \cdot 132 \pm 0.054$ \\
\hline & A & 0.672 & $0 \cdot 535$ & $0 \cdot 303 \pm 0 \cdot 111$ & $0.272 \pm 0.095$ \\
\hline \multirow[t]{2}{*}{ Inner Fjord, Ascophyllum } & $\mathrm{F}$ & $0 \cdot 420$ & 0.334 & $0.247 \pm 0.088$ & $0.215 \pm 0.074$ \\
\hline & A & 0.308 & $0 \cdot 245$ & $0.200 \pm 0.092$ & $0.171 \pm 0.076$ \\
\hline
\end{tabular}

(ii) Gregarious behaviour

\section{(a) Population means}

Lloyd's Indices of Patchiness for settlement of larvae on Fucus and Ascophyllum are given in table 4. It can readily be seen that animals from all populations are gregarious, although to varying degrees; the measurement of gregariousness for Terence Bay animals is very much less than in other populations, while animals from the Peggy's Cove and Inner Fjord, Ascophyllum populations are highly gregarious. It is noteworthy that everywhere, with the exception of the Peggy's Cove animals, gregarious behaviour is more marked on Ascophyllum than Fucus, this is partially explicable because gregarious behaviour is decreased with high settlement densities (correlation between these factors: -0.63$)$.

\section{TABLE 4}

Lloyd's Indices of Patchiness ( \pm standard error) of larvae settled on Fucus and Ascophyllum

\begin{tabular}{lcc} 
& \multicolumn{2}{c}{ Substrate } \\
\cline { 2 - 3 } \multicolumn{1}{c}{ Population } & $1 \cdot 629 \pm 0 \cdot 040$ & $2 \cdot 133 \pm 0 \cdot 049$ \\
Terence Bay & $2 \cdot 728 \pm 0 \cdot 081$ & $2 \cdot 508 \pm 0 \cdot 140$ \\
Peggy's Cove & $2 \cdot 186 \pm 0 \cdot 121$ & $4 \cdot 232 \pm 0 \cdot 516$ \\
Outer Fjord, Fucus & $1 \cdot 943 \pm 0 \cdot 046$ & $8 \cdot 356 \pm 0 \cdot 491$ \\
Outer Fjord, Ascophyllum & $1 \cdot 837 \pm 0 \cdot 034$ & $5 \cdot 051 \pm 0 \cdot 088$ \\
Inner Fjord, Fucus & $2 \cdot 786 \pm 0.073$ & $9 \cdot 768 \pm 0 \cdot 656$ \\
Inner Fjord, Ascophyllum &
\end{tabular}

It is possible the estimates of gregariousness were enhanced by differences in suitability of substrates within each petri dish, so that on the average only one or a few fronds per dish were really adequate for settlement. The results of settlement on bacterial film evenly distributed over the surface of petri dishes show this not to be true, at least for Terence Bay and Peggy's Cove populations. A highly significant difference $\left(F_{1,88}=15 \cdot 758\right)$ was 
observed between the two groups; Peggy's Cove animals (mean index of dispersion-6.1) being more gregarious than those from Terence Bay (mean index of dispersion-2:8).

\section{(b) Within population variances}

Analyses of variance of Lloyd's Indices of Patchiness on each substrate are presented in table 5 . Not all the experiments could be analysed in this manner as where the overall settling frequencies were low there were insufficient families available with over three animals settled per replicate. Of the 10 experiments thus analysed, however, significant variation among families was detected in only two, and heritabilities detected from these intra-class correlations were not significantly different from zero due to large standard errors. We must therefore conclude, on the basis of the available information, no additive genetic variation in gregarious behaviour.

\section{Discussion}

It is possible to interpret changes of mean values of characters within and between populations in terms of response to variations in selective forces known to be acting on the populations. The primary selective agent determining the probability of settlement once presented with an algal substrate must be the suitability of that alga as a substrate. It is known that Ascophyllum is inferior to Fucus as substrate for Spirorbis in that the animals do not adhere as strongly to its surface, and that this difference is particularly important in exposed or turbulent conditions, where removal from the inferior substrate is a major source of mortality (Doyle, 1975). Therefore animals from Terence Bay have substantially reduced fitness should they choose to settle on Ascophyllum rather than Fucus, and the probability of Ascophyllum settlement is only half that of Fucus settlement. Conversely, Peggy's Cove animals are selected to settle on Ascophyllum, since no other fucoid alga is available to them, and here observed settlement on Ascophyllum is twice that on Fucus. Analogously, the Fjord exhibits a clinal pattern in substrate preference (from Fucus more attractive than Ascophyllum, to both equally suitable), as one moves away from the mouth of the inlet.

Directional selection for settling strategy accounts for the interpopulation variability observed in gregarious behaviour. It is known that animals from Peggy's Cove settle more quickly than those from Terence Bay (Mackay, 1974), possibly as the result of selection in the latter habitat for a settling strategy which minimises the error made by choosing an inferior substrate and thus reducing fitness, and risking loss of fitness by prolonging planktonic existence. Then the tidepool environment is homogeneous with respect to fucoid substrate for Spirorbis, and selection would favour those individuals which settle quickly since this minimises loss of fitness due to predation and no gain in fitness is incurred by searching for a more suitable substrate. At Terence Bay, however, settlement on Fucus is of selective advantage and a longer period in the plankton increases the probability of encountering a Fucus plant. Since the gregarious response is a stimulus to settle, it is not surprising that animals selected to settle quickly (Peggy's Cove) have enhanced gregarious behaviour over those selected for longer planktonic life (Terence Bay). Although time to settlement has not been measured in the Fjord populations, one may assume similar selection pressures, as the 

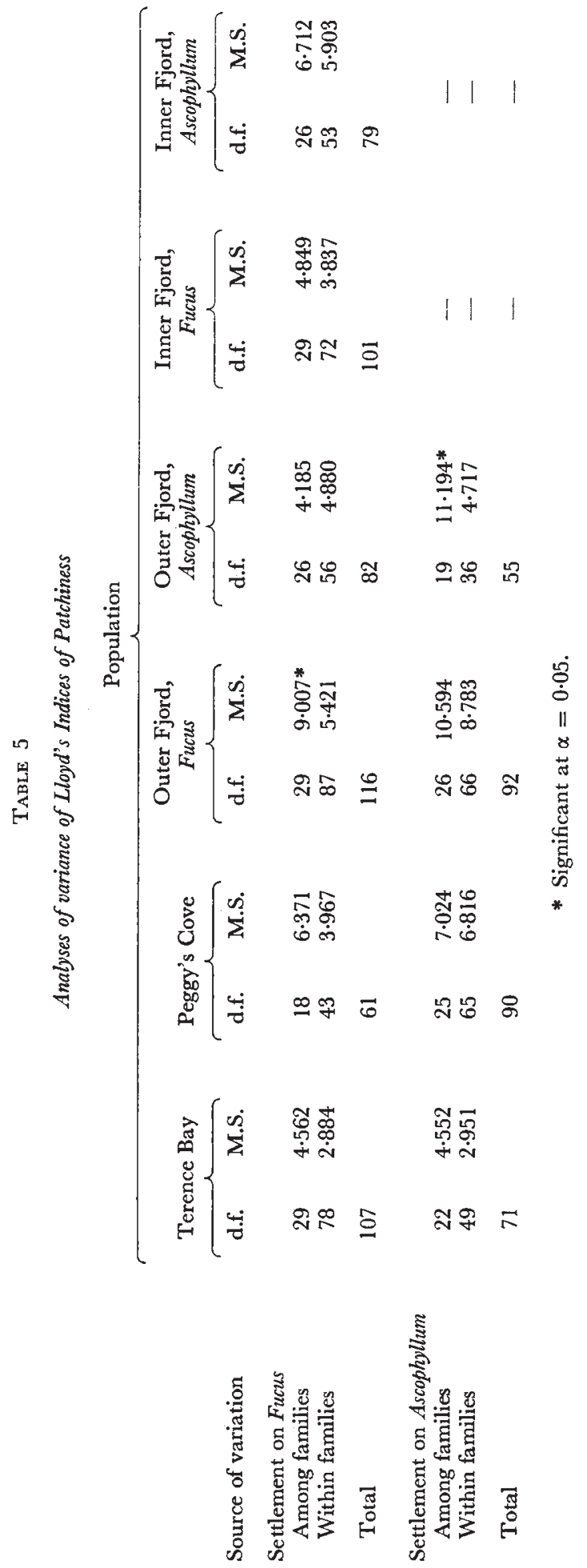
Outer Fjord, Fucus animals are definitely less gregarious than those from Inner Fjord, Ascophyllum.

One can infer adaptation of populations to varying selection pressures from analysis of interpopulation differentiation of character means, but it is from study of the within population genetic variances that we have an indication of the mode of such adaptation. There are basically two mechanisms by which a population may adapt to a heterogeneous environment, either by increased individual homeostasis, or by genetic differentiation such that fitnesses of the genotypes vary in the alternative habitats. If the character studied is quantitive or metric, the two mechanisms can be distinguished on the basis of the genotype-environment interaction (a measure of the extent to which a given trait expressed under different environmental conditions is controlled by the same set of genes); one expects no interaction if the population is responding to environmental heterogeneity by the first mechanism, while if genetic differentiation is the mode of adaptation such interaction would be present.

A more elaborate experimental design than that employed here is necessary to estimate interactions, but the pattern of differences in heritability of settlement between substrates within each of several of the populations studied (in which the point estimate of heritability differs according to substrate) is certainly suggestive of an interaction of genotype with environment. We may therefore tentatively attribute differences in mean settlement on the two substrates within populations to actual genetic differentiation. It is not possible to deduce interaction by comparison of calculated heritabilities of gregarious behaviour, as they were not significantly different from zero nor from each other. Although there are few experimental studies of mechanisms of population adaptation to heterogeneous environments to which this work may be compared, the conclusion from this study and from the earlier work of Antonovics and his colleagues (e.g. Antonovics, 1971) must be that there is increasing evidence of adaptation to varying ecological conditions within populations due, at least in part, to precise genetic differentiation.

Acknowledgments.-We wish to thank Drs G. Newkirk and L. Haley for helpful and interesting discussions, and L. Richard and A. Finley for technical assistance at critical moments. T. F. M. was supported by National Research Council of Canada and Killam Postgraduate Scholarships.

\section{REFERENCES}

Antonovics, J. 1971. The effects of a heterogeneous environment on the genetics of natural populations. Am. Sci., 59, 593-599.

BARNES, B. W., AND KEARSEY, M. J. 1970. Variation for metrical characters in Drosophila populations. Heredity, 25, 1-10.

BUTCHER, A. C., GROFT, J., AND GRINDLE, M. 1972. Use of genotype-environmental interaction analysis in the study of natural populations of Aspergillus nidulans. Heredity, 29, 263-283

Chapman, A. R. o. 1974. The genetic basis of morphological differentiation in some Laminaria populations. Mar. Biol., 24, 85-91.

DEMPSTER, E. R., AND LERNER, I. M. 1950. Heritability of threshold characters. Genetics, 35, 212-236.

DOYLE, R. w. 1974. Choosing between darkness and light: The ecological genetics of photic behaviour in the planktonic larvae of Spirorbis borealis. Mar. Biol., 25, 311-317.

DOYLE, R. W. 1975. Settlement of planktonic larvae: a theory of habitat selection in varying environments. Amer. Natur., 109, 113-126. 
FORD, E. B. 1965. Ecological Genetics. Methuen and Co., Ltd. London.

GALE, J. s., SOlOMON, R., THOMAS, W. T. B., AND zUBERI, M. I. 1976. Variation in wild populations of Papaver dubium. XI. Further studies on direction of dominance. Heredity, 36, 417-422.

KEARSEY, M. J., AND KOJIMA, K. I. 1967. The genetic architecture of body weight and egg hatchability in Drosophila melanogaster. Genetics, 56, 23-37.

Kempthorne, o. 1969. An Introduction to Genetic Statistics. Iowa State University Press.

KNIGHT-JONEs, E. w. 1951. Gregariousness and some other aspects of the setting behaviour of Spirorbis. F. Mar. Biol. Assoc. UK., 30, 201-222.

KNIGHT-JONEs, E. W. 1953. Decreased discrimination during settling after prolonged planktonic life in larvae of Spirorbis borealis (Serpulidae). 7. Mar. Biol. Assoc. U.K., 32, 337. 345.

KNIGHT-JONES, E. W., BAILEY. J. H., AND ISAAC, M. J. 1971. Choice of algae by larvae of Spirorbis spirorbis. Fourth European marine biology symposium. Cambridge University Press.

KoEHN, R. K., AND RASMUSSEN, D. J. 1967. Polymorphic and monomorphic serum esterase heterogeneity in catastomid fish populations. Biochem. Genet., 1, 131-144.

LAWRENCE, M. J. 1965. Variation in wild populations of Papaver dubium. I. Variation within populations; diallel crosses. Heredity, 20, 183-204.

LUSH, J. L., LAMOREUX, W. F., AND HAZEL, L. N. 1948. The heritability of resistance to death in the fowl. Poult. Sci., 27, 375-388.

MACKAY, T, F, C, 1974. Ecological genetics of some aspects of the settling behaviour of larvae of Spirorbis borealis (Daudin). Hons. Thesis, Dalhousie University, Halifax, N. S., Canada.

NEWKIRK, G. F., AND DOYLE, R. W. 1975. Genetic analysis of shell shape variation in Littorina saxatilis on an environmental cline. Mar. Biol., 30, 227-237.

PIElou, E. c. 1974. Population and Community Ecology: Principals and Methods. Gordon and Breach.

ROBERTSON, A., AND LERNER, 1. $M$. 1949. The heritability of all or none traits: viability of poultry. Genetics, 34, 394-411.

SCHOPF, T. J. M., AND GOOCH. J. L. 1971. Gene frequencies in a marine ectoproct: a cline in natural populations related to sea temperature. Evolution, 25, 286-289.

DEsILVA, P. H. D. H. 1958. Use of artificially liberated larvae in experiments on the settling behaviour of Spirorbis. Nature, 182, 1751-1752.

DEsilva, P. H. D. H. 1962. Experiments on choise of substrata by Spirorbis larvae (Serpulidae) F. $\exp$. Biol., 39, 483-490.

SIMCHEN, G. 1967. Independent evolution of a polygenic system in isolated populations of the fungus Schizophyllum commune. Evolution, 21, 310-315.

sokal, R. R., AND Rohlf, F. J. 1969. Biometry: The Principles and Practise of Statistics in Biological Research. W. H. Freeman and Company.

WISEBY, B. 1960. Observations on the settling behaviour of larvae of the tubeworm Spirorbis borealis Daudin (Polychaeta). Aust. F. Mar. Freshw. Res., 11, 55-72.

WRIGHT, s. 1933. An analysis of variability in number of digits in an inbred strain of guinea pigs. Genetics, 19, 506-536.

WRIGHT, s. 1934. The results of crosses between inbred strains of guinea pigs, differing in number of digits. Genetics, 19, 537-551. 